Article

\title{
Emotional State and Social Media Experience: A Pandemic Case Study
}

\author{
Olga Vl. Bitkina and Jaehyun Park* *1
}

check for

updates

Citation: Bitkina, O.V.; Park, J. Emotional State and Social Media Experience: A Pandemic Case Study. Sustainability 2021, 13, 13311. https:/ / doi.org/10.3390/su132313311

Academic Editor: Carlos Salavera

Received: 9 October 2021

Accepted: 29 November 2021

Published: 1 December 2021

Publisher's Note: MDPI stays neutral with regard to jurisdictional claims in published maps and institutional affiliations.

Copyright: (c) 2021 by the authors. Licensee MDPI, Basel, Switzerland. This article is an open access article distributed under the terms and conditions of the Creative Commons Attribution (CC BY) license (https:/ / creativecommons.org/licenses/by/ $4.0 /)$.
Department of Industrial and Management Engineering, Incheon National University (INU), Incheon 22012, Korea; olgabitkina@inu.ac.kr

* Correspondence: jaehpark@inu.ac.kr

\begin{abstract}
The world has been experiencing an unprecedented global pandemic since December 2019. Lockdowns, restrictions in daily life, and social distancing characterize the new environment in which the world population finds itself, with minor variations depending on the country of residence. Television, social media, and other sources of information tend to influence and provide information about COVID-19 with varying tones. This study investigated the impact of alerts, news, and information about COVID-19 from social and mass media on the emotional state of the people a year and a half after the start of the pandemic. A questionnaire was developed and distributed to 63 participants to assess the relationships between factors such as social media experience, perceived hope, worry, anxiety/depression, attentiveness, trust, health care, health risk, health safety, irritability, mental balance, and emotional state/distress. With the resulting information, a four-factor model was developed to demonstrate the relationships between social media experience, perceived hope, worry, and emotional state/distress. Additionally, a short interview was conducted among the participants in order to collect their opinions and qualitatively analyze them. The developed model demonstrates satisfactory performance characteristics and allows assessment of the delayed influence of incoming information on the people during this unprecedented pandemic.
\end{abstract}

Keywords: COVID-19; pandemic; social media experience; factor analysis; emotional state; coronavirus

\section{Introduction}

The end of 2019 brought the world news of a new type of pneumonia discovered in Wuhan, Central China's Hubei Province [1]. The definition of coronavirus disease 2019 (2019-nCoV; COVID-2019; COVID-19) was officially introduced by the World Health Organization on February 11, 2020 [2]. This moment became a turning point for the lives of the entire world population. Country governments began to take various restrictive measures to reduce the spread of COVID-19, such as lockdowns, social distancing, and restrictions on daily life and traveling. All of these factors, combined with the novelty and unexpectedness of the pandemic, directly influenced people's mental state [3]. Social media played a role in this, with previous research showing that media use increased during lockdown [4]. This study compared social media use before and after the beginning of the pandemic period. Analysis showed that weekly social media use was growing consistently during a pandemic by $4.2 \mathrm{~h}$ on average. Additionally, nearly $40 \%$ of survey participants reported increased weekly social media use by $3.5 \mathrm{~h}$. Social media has become the main source of information about coronavirus infection, and because of the intensity and frequency of incoming news and warnings, the population has become more restless and anxious [5-7]. The study in [8] reported that about $45-62 \%$ of survey participants felt horrified and apprehensive during the COVID pandemic. Additionally, over $40 \%$ of respondents have experienced increased stress from financial perspectives. However, more than a year has passed since the beginning of the pandemic; people are, to some extent, accustomed to the new reality, and their attitude toward incoming information about 
COVID-19 has changed as well [5]. It was found that attitudes of people are changing towards adaptation to the new pandemic reality and information topics, but this does little to contribute to the feeling of wellbeing. This means that adaptation does not reduce mental stress. Some sources report [9] that, in the beginning/middle of the pandemic, the usage of alcohol and psychoactive substances, incidence of anxiety and depressive disorders, and rate of suicide increased across almost all countries. Social surveys show that the use of health-damaging methods to reduce stress and anxiety was increased around the world during the pandemic $[9,10]$. Nearly $60 \%$ of survey participants reported growth of alcohol consumption during the pandemic period. Pandemic stress as a reason for alcohol consumption was reported by $45.7 \%$ of respondents. Generally, the fact that stressed participants showed more frequent antisocial behavior is a cause for high public health concern [9]. The main reasons for this were a slowdown in the pace of life, reduced social contact, reductions in or loss of work, changes in the level of income, etc. Due to the decline in real-world social contact, people spend more and more time on social networks and watching TV and Internet programs [4].

An online European survey shows that about $50 \%$ of the German and about $60 \%$ of the Italian participants use different social media to obtain information about COVID-19 [11]. The analysis supports the hypothesis about the connection between social media use, user stress, and burden.

According to the above research and facts, of particular interest in the present study are changes in people's attitudes toward COVID-19 based on incoming news about coronavirus $[4,5]$. The original research hypothesis was to test the relationship between human emotional states and social media experiences. This study will provide results and new data for both the psychological and behavioral sciences and information and health professionals. The obtained results will help to better understand the relationship between the information consumed and the mental state of people in emergency situations from a scientific point of view. From a practical viewpoint, this study will provide a basis for the development of principles for the spreading of important information in such a way as to reduce the negative impact on the mental health of the user. A detailed discussion of the choice of the investigated factors is presented in the Literature Review section.

\section{Literature Review}

\subsection{Relationships between Influencing and Responding Variables}

In the present study, the influencing variable was social media experience (SME), and the responding variable was mental state/distress (MSD). SME was considered as all types of use, conversation, and engagement on the various platforms to receive feedback, news, and alerts about COVID-19, including online media, TV, newspapers, and journals [12,13]. MSD refers to the emotional and mental state of a person, especially with regard to negative feelings of stress and panic [13].

SME impacts users' mental states in negative and positive ways [12,14]. The main positive aspects of SMEs regarding mental state can include relief from negative feelings, promotion of healthcare, growth of hope for the future, and feelings of gratitude for the provided COVID information. Negative impacts include points such as increases in distress, fear for health, hopelessness, and anxiety about COVID information [12,13]. An additional double effect is that, using information from the news about COVID-19, people are motivated to take precautions, such as social distancing, but at the same time, they begin to trust the advice of unsubstantiated medicine [14]. The world's population has faced not only negative mental consequences but also physical ones [15]. Mortality rates have increased, especially among the population over 60 years of age. In turn, life expectancy at birth has been declining since 2019.

The study in [4] found that weekly social media use increased significantly during the pandemic period. This was associated with an increase in distress, anxiety, and depression rates. Moreover, social media addiction has also increased during the COVID-19 pandemic. Research [16] showed that fake news about COVID-19 can significantly affect the perception 
and emotional state of the population. The mental health of young people in the United Kingdom was studied in terms of social media use during the pandemic [17]. This study found that an overload of information about COVID-19 through social media has a negative effect on the mental wellbeing of the young members of Generation Z. Particularly, social media fatigue and fear of COVID-19, together with the intention to discontinue social media, increased. People's perception of social media information about COVID-19 was studied in relation to individual health [18]. In particular, preventive behavior and social media consumption were found to be connected through health orientation factors. Study [19] reported that passive social media use increases loneliness and decreases life satisfaction, but active use of social media positively influences affect while increasing loneliness. This study also supported previous findings of the increase in social media use during the pandemic, but people's connections with family and friends online have decreased. Social media use [20] is associated with the development of depression and affects the mental state of young adults. Moreover, positive relation between perceived social media use and the spread of COVID 19-related panic was found in a study [13]. An online survey [21] showed the impact of SMEs on MSD. The authors reported that problematic social media use is related to decreased real-life social support and increased social support on social media. At the same time, social support on social media does not positively affect mental health. Another mental characteristic, envy, was found to be related to depression and SME [22]. The results supported a positive connection between mobile social media use and depression, which is mediated by envy. Moreover, a positive relationship between mobile social media use and depression according to social comparison was found in adults with lower marital satisfaction.

Social media are open forums to express distress and find support [23]. The analysis showed support for the relationship between SME and negative emotions and behaviors such as distress, blaming, and self-harm. The authors proposed the recognition of emotional response types to prevent negative reactions among young people. Distress among students during the COVID pandemic using social media was studied [24]. The results showed a connection between SME and depression, anxiety, and stress. Female students demonstrated higher levels of depression and anxiety symptoms. Moreover, the academic usage of social media correlated negatively with distress scores, but entertainment media had a positive correlation with anxiety. Social anxiety and depression were studied in relation to SME and time of social media use on psychological distress over time [25]. Increased time spent using social media was significantly correlated with an increase in distress symptoms. Moreover, these symptoms increased with time. Female participants showed higher levels of distress, depression, and anxiety. Mental state and distress were studied among Malaysians during the pandemic [18]. According to the obtained results, using social media and news was associated with increased anxiety, but at the same time, after the beginning of the pandemic, some people reported that they checked the latest news about the coronavirus to improve their mental state.

Based on the correlations shown in previous studies, the main factors were selected as SME and MSD. The main relationships and influence between SME and MSD investigated in the above studies are summarized in Figure 1. Figure 1 reflects the trends in COVIDrelated literature indicating that the pandemic influences social media experience and mental state. 


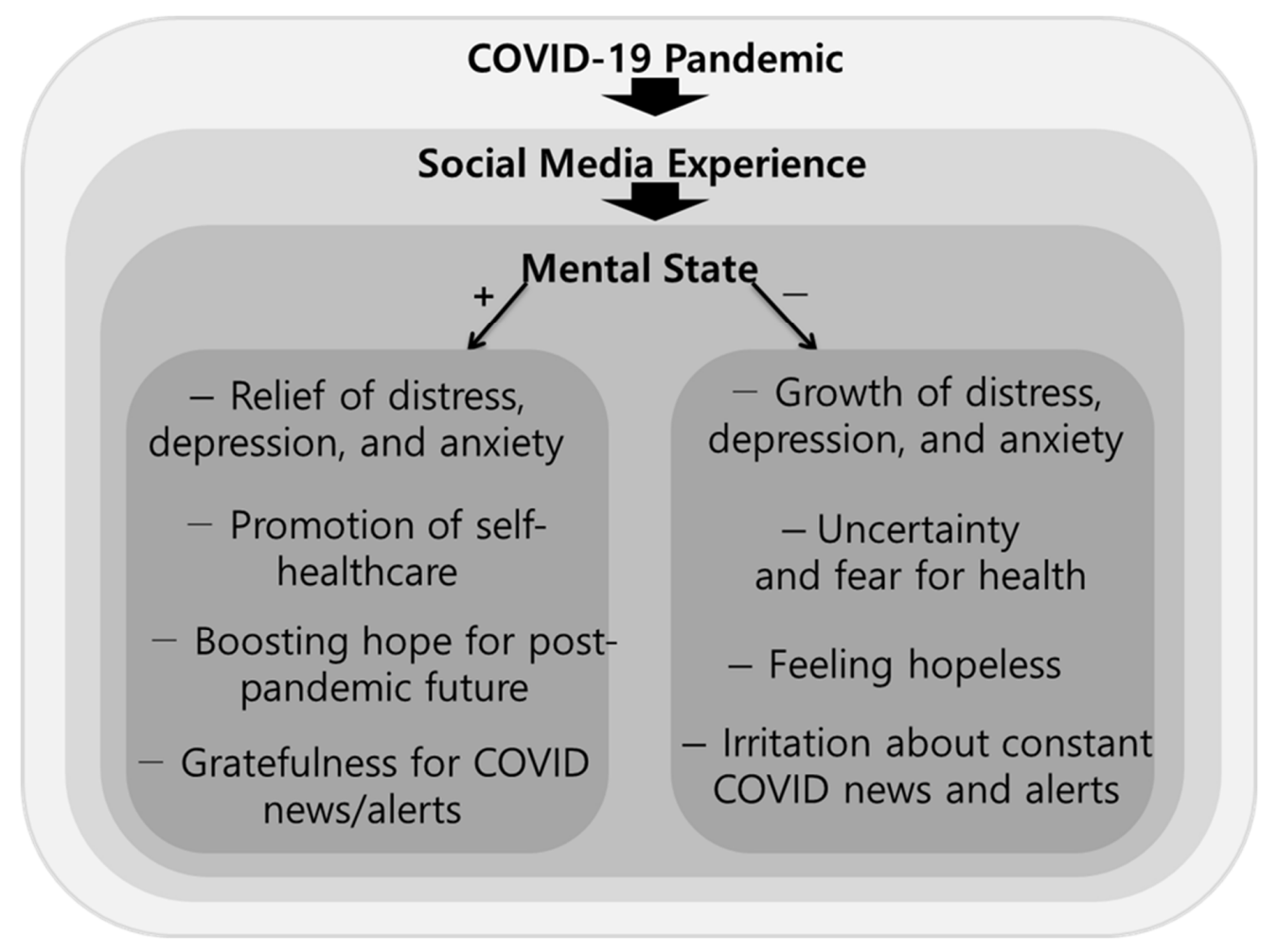

Figure 1. Relationships between mental state and SME determined in previous studies.

\subsection{Buffering Variables: Relationships and Mutual Influence}

In previous studies, the analyzed buffering factors were discussed simultaneously and shown to have mutual influence, including MSD and SME. A study [26] showed the impact of various types of COVID-19 information on public worry using a cross-sectional online survey in the context of distress. It was found that information from traditional media, internet media, and friends caused higher current worry. Information from friends was also associated with past worry. Academic courses providing COVID-19 information were related to lower past and anticipated worry. A US national survey [27] suggested that worry is a mediator that positively connects social media use and misinformed beliefs, while discussion heterogeneity preference is negatively associated with misinformed beliefs. Another online survey [28] was performed among Italians to investigate worry and anxiety. The authors proposed that worry mediates the relationship between coping strategies and anxiety during the COVID-19 pandemic. Moreover, psychological wellbeing depends on worry levels. COVID-related worries [29] were investigated in daily life at the beginning of the pandemic. It was shown that occupation and worry co-occurred, and occupation predicted worry. In turn, neuroticism did not predict any relationship between worry and occupation. An empirical study [30] showed the relationship between mass media information and worries and connections in the context of an immigration employee workplace. Previous research [31] also has proven population fatigue from being in pandemic isolation. This fatigue is more pronounced among women, especially if the isolation lasts more than six months.

Research [32] showed the influence of hope on post-stress growth regarding perceived stress during a pandemic. Hope is positively associated with post-stress growth but negatively associated with perceived stress. The empathy factor is a buffer between hope and perceived stress.

Previous studies have shown that trust is connected with mass and social media use and human behavior $[33,34]$. The quality of the information in social media is related to the perceived government response to COVID-19 and public trust [33]. Trust in social media information is dependent on users' behavior regarding fulfilled expectations, predictability, familiarity, monitoring, and norms [34]. 
Anger, irritability, and anxiety were studied [35], according to social media information. It was found that the emotional response of readers depends on the emotional coloring of information and the number of anger-related words in posts. With an increase in the number of anger-colored words, the number of news reposts increased. Anxietycolored information shows a reduction in reposts for users with high numbers of followers. Perception of health (safety, risk, and care) depends on psychological distress [36]. The study provides evidence that distress impacts physical health status, illness behavior, and the use of medical care. The socially evaluated cold pressor test was performed by [37] to evaluate attentiveness and stress relations. Stress was found to be negatively correlated with attentiveness. Mental balance and distress were found to be directly correlated. Emotional (mental) balance reduces distress. Mental responses of the United Kingdom (UK) population related to depression and anxiety were found in the early stage of the pandemic [38]. Moreover, it seems that economic changes are associated with psychiatric symptoms of the UK population. Based on previous literature sources, the factors for modeling the mental state of the population during the COVID pandemic were extracted.

In the present study, ten buffering variables based on the above literature review were selected as follows: perceived trust (PT), perceived health care (PHC), perceived health safety (PHS), perceived attentiveness (PA), perceived hope (PH), perceived health risk (PHR), perceived irritability (PI), perceived anxiety/depression (PAD), perceived mental balance (PMB), and perceived worry (PW). This choice was based on the fact that the above studies have shown a relationship between buffering, influencing, and being influenced variables. The context of the studied factors is shown in Table 1.

Table 1. Context of buffering variables.

\begin{tabular}{|c|c|c|}
\hline Variable (Factor) & Context & Reference \\
\hline PT & "Feeling of security and willingness to depend on someone or something (social media information)" & [39] \\
\hline PHC & $\begin{array}{c}\text { Feeling of "ability of individuals to promote health, prevent disease, maintain health, and cope with illness } \\
\text { without the support of healthcare providers" }\end{array}$ & [40] \\
\hline PHS & $\begin{array}{c}\text { Feeling of "an individual's experience of the risk of becoming a victim" (a victim of COVID-19 in the } \\
\text { present study) }\end{array}$ & [41] \\
\hline PA & $\begin{array}{l}\text { Feeling of "the state of being constantly attentive and responsive to signs of opportunity, activity, or } \\
\text { danger" (with regard to COVID-19 in the present study) }\end{array}$ & [42] \\
\hline $\mathrm{PH}$ & $\begin{array}{c}\text { "Perceived capability to derive pathways to desired goals and motivate oneself via agency thinking to use } \\
\text { those pathways" }\end{array}$ & [43] \\
\hline PHR & "The subjective assessment of the possibility of suffering negative health events over a specified period" & [44] \\
\hline PI & "Feelings of anger or frustration that often arise over even the smallest of things" & [45] \\
\hline PAD & $\begin{array}{l}\text { Feelings of depression and anxiety symptoms such as "nervousness, irritability, and problems sleeping and } \\
\text { concentrating" }\end{array}$ & [46] \\
\hline PMB & Feelings of "the healthy psychological state of someone with good judgment" & [47] \\
\hline PW & Subjective assessment of "streams of verbal thoughts about potential negative outcomes" & [48] \\
\hline
\end{tabular}

\section{Materials and Methods}

\subsection{Participants}

Sixty-three randomly selected participants (27 males and 36 females) volunteered for this experiment and the accompanying questionnaire. The survey study was announced on the online bulletin board, and questionnaires were sent to interested participants by e-mail. The average age of participants was 40.5 (standard deviation: \pm 8.56 years). All participants were Korean and belonged to one of three groups: employed (33 people), self-employed or freelance (19 people), or unemployed (11 people). The purpose and procedure of the experiment were explained to participants in advance. Participants were informed that they could discontinue the experiment at any time. This study was conducted in compliance with the Declaration of Helsinki. 


\subsection{Experiment}

In the experiment, the influence of social media usage on the mental state (distress) in the pandemic was analyzed based on the factors of perceived hope, worry, anxiety/depression, attentiveness, trust, health care, health risk, health safety, irritability, and mental balance. The questionnaire (Appendix A) was developed based on previous research on perceived mental characteristics after using social media and alert information [49-52]. The evaluation of all studied factors was performed using a scale from 0 (lowest) to 10 (highest).

The questionnaire development process was without critical changes and revisions of the previously validated questionnaires related to the psycho-emotional state of the people. Questionnaires and studies with many years of experience in use [49-51] and new surveys and research previously validated on the subject of COVID-19 and people's behavior [13,52] were combined and validated by survey participants. To do this, we carefully monitored the correspondence of all questions with the source and also made sure that the participants understood the questions and the research topic and also that the questions reflected the essence of the research topic. The validation of the questionnaire was satisfactory, and the survey participants confirmed the usability of this measuring tool.

During the survey presented, questionnaires were administered to 63 participants, who completed the survey within one to two days. The questions were not shown to the participants in advance. During the initial assessment of the survey results, the full set of obtained responses was used without omissions. During the survey, no complaints from the participants or problems with the experimental procedure were identified.

Additionally, mini-interviews with 15 randomly selected participants were conducted to obtain a more detailed view of the pandemic. During the interview, the participants answered three questions:

(1) How did the pandemic affect your social media use and news checking early in the pandemic in 2020 and closer to September 2021?

(2) Have you noticed a connection between the pandemic, social media use, and depression, anxiety, or stress state? Is there a difference in this matter at the very beginning of the pandemic in 2020 and closer to September 2021?

(3) Have you noticed a connection between the pandemic, social media use, and perceived characteristics such as hope and worry? Is there a difference in this matter at the very beginning of the pandemic in 2020 and closer to September 2021?

During the interview, no complaints from the participants or problems with the experimental procedure were identified.

\subsection{Analysis}

Exploratory factor analysis (EFA) was performed using SPSS software to identify the relationships between measured variables and determine the underlying structure of the existing set of variables. The initial factor model had sets of manifest variables (SME1-SME10, PH1-PH10, etc.), which are functions of common factors (SME, PH, PW, PAD, etc.). EFA was performed using varimax rotation to extract the optimal three-factor solution. Common factors influence the manifest variables; Cronbach's alpha for each factor and "factor loadings" for each factor was obtained to measure the impact of common factors on a manifest variable.

Confirmatory factor analysis (CFA) was performed using AMOS software to verify the factor structure based on the manifest variables. The presented CFA is based on a four-factor solution determined through EFA and shows the existing relationships between factors and observed variables. Satisfactory results with goodness-of-fit (GOF) indexes were obtained.

The results of the interviews were qualitatively assessed and summarized. The main common points and trends in the relationship between social media, pandemics, and mental health were highlighted and presented in the Results section. 


\section{Results}

\subsection{Exploratory Factor Analysis}

Exploratory factor analysis was performed to assess the consistency of the originally developed questionnaire and highlight significant factors. The results of EFA suggest nine factors (F) with a set of items (I) based on the varimax rotation of the studied characteristics with the highest correlations (Appendix B).

Appendix B shows the selected items with the highest correlations (loading) with factors. The items (variables) were selected using the following criteria:

- Selecting questionnaire items with loadings above 0.5;

- $\quad$ Screening for factors whose questionnaire items were less than 2;

- Screening out questionnaire items whose loadings were above 0.5 for a few factors at the same time.

Based on the above criteria, a nine-factor model was extracted using various items. Cronbach's alpha shows values between $0.75-0.95$ for each factor, indicating satisfactory correlations between the set of items as a group.

\subsection{Confirmatory Factor Analysis}

After performing CFA, the number of factors was reduced to a four-factor model to fit the performance indexes and satisfactory factor loading results (Table 2). The main goodness-of-fit indexes are shown in Table 2, and the extracted model is shown in Figure 2.

Table 2. CFA goodness-of-fit indexes.

\begin{tabular}{cc}
\hline Parameter & Value \\
\hline Incremental fit index (IFI) & 0.944 \\
Root mean square error (RMSEA) & 0.072 \\
Comparative fit index (CFI) & 0.944 \\
Relative chi-square (CMIN/DF) & 1.322 \\
\hline
\end{tabular}

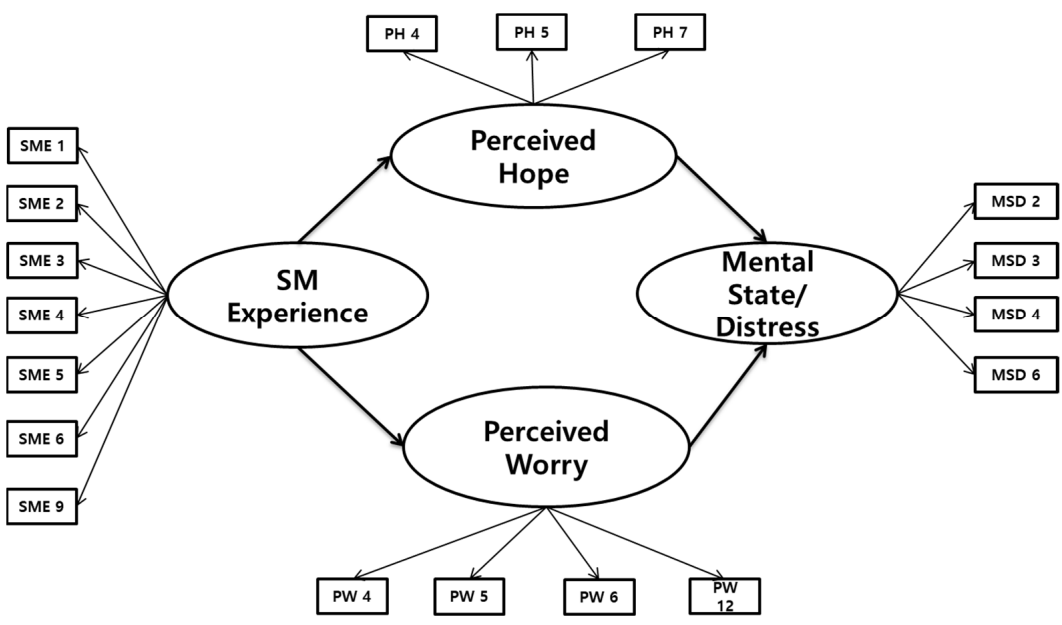

Figure 2. Extracted CFA model.

Figure 2 shows the CFA model with factor loadings of above 0.5 and that correlations between factors and extracted variables are satisfactory. The model goodness-of-fit indexes (Table 2) show satisfactory results: IFI and CFI $>0.9, \mathrm{CMIN} / \mathrm{DF}<2$, and RMSEA $<0.08$. Generally, the EFA and CFA results are acceptable and demonstrate the adequacy of the developed four-factor model.

\subsection{Interview Results}

The results of the interviews made it possible to highlight the following common features after a qualitative assessment: 
- At the beginning of the pandemic, people checked the news about COVID-19 and social media much more often compared to September 2021. Participants noticed a connection between the news and their emotional state. This link was stronger at the start of the pandemic compared to September 2021.

- In most cases, people in early 2020 felt much more anxiety, and depressive moods were less common. Anxiety was related to their own health, as well as the health of relatives and friends. In the period closer to September 2021, anxiety and depression decreased.

- People always felt a high level of hope for an end of the pandemic, but by September 2021, this feeling had grown. There was almost no feeling of hopelessness among participants.

- There is a general trend of mental fatigue towards a decrease in negative emotions and an improvement in the mental state over the course of the pandemic. Additionally, checking the news about COVID-19 and interest in this topic is gradually decreasing.

Summing up the interview results, it was found that there is no critical difference in the opinions of people of different ages and genders. The interview data are generally consistent with the survey results.

\section{Discussion}

The aim of this study is to assess the impact of incoming news about COVID-19 from social media on the emotional state of people. To accomplish this, a questionnaire was developed, and a survey was conducted among representatives of different ages and strata of the population. The survey results were accessed through factor analysis, which showed that social media experience directly affects worry and hope, which, in turn, affect the emotional state/distress of people.

A four-factor model consisting of experience with media, hope, worry, and emotional state/distress was obtained. It should be emphasized that these results correspond to the period of one and a half years after the start of the pandemic. Previous studies conducted at the beginning of the pandemic reported that depression and anxiety played a significant role in the emotional and psychological states of the population [53]. A study [54] found a positive correlation between stress during the pandemic and depression. In turn, character strength plays a significant role in stress and depression management. More morally strong people deal with the negativity of the pandemic more easily. Concern about COVID-19 and discrimination against people based on race, financial distress, and infection are correlated with moderate or severe depression [55]. In turn, concerns about the pandemic, financial distress, and infection are related to moderate or severe anxiety. A clinical study [56] found that, during COVID-19, the first-line medical staff had anxiety and depression. Early psychological intervention reduces anxiety but does not affect depression. In contrast to previous studies, research was connected to one SME model and stress through perceived characteristics of worry and hope more than a year after the pandemic started. Previous studies have focused on evaluating the impact of pandemic duration on emotional states without examining media use $[5,8,9]$. In turn, studies accounting for media impact have used fewer buffer variables between media experience and users' emotional state analysis [6]. Obviously, with the passage of time since the beginning of the pandemic, feelings of hopelessness and depression have been replaced by hope and worry, which are associated with ideas of the future after the pandemic. It can be assumed that this is based on ongoing vaccination, the expectation that the end of the pandemic is approaching, and the return of normal life; a pandemic cannot last forever, and the more time passes, the closer the end of this abnormal period is.

Our main finding is that news about the pandemic directly affects worry and hope, which, in turn, affect emotional state/distress in opposite ways. This means that when hope rises, stress decreases, and when anxiety rises, stress increases. This finding is consistent with the results of previous research [57]. Television and web media contribute to the growth of fear and worry about COVID-19 in the working population because the news 
is accessible at any time of day and night. These findings suggested that users should reduce media use to prevent negative effects on mental health. Levels of worry and anxiety are significantly increased if an individual frequently uses media and personally knows infected people or lives in an area with confirmed cases [58]. Worry was found to be a factor amplified by media news and supports protective behaviors among populations against threats [59]. A positive relationship between media consumption (frequency, duration, and diversity) and distress / worry-related factors was found by [60]. The authors suggested careful consumption of information to prevent a negative impact on users' mental states.

Hope is a protective factor against negative emotional states, and in turn, hopelessness contributes to depression [61]. In this study, the authors proposed the idea of "hopeless depression" and conceptualized the role of hope in the mental state of the population. Hope neutralizes signs of distress and depression [62]. Previous studies have shown that hope cannot disappear completely but can be transformed depending on time, environment, and conditions [63]. A study [64] supported the idea that hope is changeable over time and state among cancer patients.

In addition, the results obtained confirm the previous conclusions that the emotional tone of the news greatly affects perception and can cause two opposite emotions: worry and hope. This suggests that incoming information is an influential tool that can be used to achieve tasks of public importance. One example of manipulation is a moral panic, which was escalated to a certain extent during the pandemic period [65]. "A moral panic is a widespread feeling of fear, often an irrational one, that some evil person or thing threatens the values, interests, or wellbeing of a community or society. It is 'the process of arousing social concern over an issue,' usually perpetuated by moral entrepreneurs and the mass media, and exacerbated by politicians and lawmakers" [66]. Due to their availability, social networks and media-based alerts have become a tool for influencing people's behavior and fostering collective actions [44,67]. Moreover, online media, news, and alerts contribute to increased anxiety, hostility, and irritability, which result from media-induced panic [68,69].

The interview showed a general trend of the decrease in negative emotions and an improvement in the mental state through the pandemic period due to hope for the future and mental fatigue of the pandemic state. Additionally, checking the information about COVID-19 on social media is gradually decreasing. The previous study performed in the UK found that the population responded more strongly to depression and anxiety in the early stage of the pandemic [38]. Spain's population showed behavioral changes related to the pandemic period as well [31]. It was found that psychological state plays an important role during pandemics and isolation. Usually, after six months of self-isolation, people experience psychological fatigue, and their willingness to be isolated decreases despite the potential danger of infection. These findings support the obtained interview results about changes in human perception of pandemics over time.

The present study demonstrates an obvious relationship between media consumption, worry, hope, and emotional state/distress in the media users during a pandemic. Based on these results and those of previous studies, it is recommended that people should be cautious and critical about consuming incoming information about COVID infection and the pandemic. It would also be useful to limit access to social media, television, and news. Finally, it is also necessary to mention the responsibility of the media in disseminating information and influencing public opinion and the mental state of the population.

\section{Limitations of This Study}

The presented study has a few limitations that need to be mentioned-first, the number of survey participants. In future studies, the number of respondents and the variety of countries involved in the experiment will be increased to extend the results to a wider population. Secondly, the methods for analyzing the survey data obtained can be expanded. The regression analysis, T-test, and analysis of variance can also be used together with factor analysis to obtain additional conclusions for a wider population. Thirdly, during the 
experiment, both quantitative and qualitative data can be collected and analyzed to build more accurate models for assessing the mental state of the participants.

\section{Conclusions}

In this study, a four-factor model, consisting of experience with media, hope, worry, and emotional state/distress, was obtained. The model yielded satisfactory results in terms of efficiency and factor load parameters. Our main finding is that news of a pandemic directly affects anxiety and hope, which, in turn, affect emotional state/distress in opposite ways. This means that when hope rises, stress decreases, and when anxiety rises, stress increases. The results suggest that the emotional tone of information significantly affects the mental state of people in moments of perceived uncertainty and potential danger. This confirms the manipulative nature of emerging psychological states. These results also lead to the conclusion that the media should be more responsible when presenting the information. Furthermore, a questionnaire was developed with highlighted items to adequately assess the interaction between media, hope, worry, and emotional state/distress. This model can be used by itself or incorporated into existing methods to assess emotional states in the population in unpredictable situations.

Author Contributions: Writing—original draft preparation, O.V.B.; writing—review and editing, J.P. All authors have read and agreed to the published version of the manuscript.

Funding: This work was supported by Research Assistance Program (2020) in the Incheon National University.

Institutional Review Board Statement: Not applicable.

Informed Consent Statement: Informed consent was obtained from all subjects involved in the study.

Data Availability Statement: The data used for this study is available upon request.

Conflicts of Interest: The authors declare no conflict of interest.

\section{Appendix A. Questionnaire Items}

Table A1. Social media experience during pandemic.

$$
\text { Question }
$$

I frequently use social media and receive alerts about the coronavirus

I use a few types of media (Internet, TV, booklets, etc.) to check information and updates about the coronavirus

I like to use the media and alerts to check information and updates about the coronavirus

I can get all information and updates about the coronavirus that I need from media and alerts

I get the most information about the coronavirus from media and alerts

Every day, I check for updates and new information about the coronavirus using social media and alerts

I don't like to use the media and alerts to check for information and updates about the coronavirus

Social media and alerts have proven to be useless to get information and updates about the coronavirus

Social media and alerts have proven to be useful to get information and updates about the coronavirus

I avoid using social media and alerts to get information and updates about the coronavirus

Table A2. Emotional State during pandemic.

I feel nervous more often than usual during the pandemic

I feel hopeless more often than usual during the pandemic

I feel restless or fidgety more often than usual during the pandemic

I feel "so depressed that nothing could cheer me up" more often than usual during the pandemic

I feel that "everything is an effort" more often than usual during the pandemic

I feel worthless more often than usual during the pandemic

My emotional state in the pandemic is no different from usual

I feel harmonious during the pandemic

I feel relaxed during the pandemic

I feel psychological comfort during the pandemic

I feel caring for yourself during the pandemic is more than usual 
Table A3. Trust during pandemic.

Question

The general information about the coronavirus in media is deceptive

Media sources behave in an underhanded manner when spreading the news about the coronavirus

I am suspicious of the media's intent, action, or output regarding the coronavirus

I am worried about the news about the coronavirus

I am confident in media sources

Media sources have integrity

The news about the coronavirus is dependable

Media sources are reliable

I can trust the media

I have positive experiences with media

Table A4. Healthcare during pandemic.

\begin{tabular}{c} 
Question \\
Score \\
Healthcare information providers (media) are good at explaining how to deal with the coronavirus \\
I believe that healthcare information providers (media) have the latest information about the coronavirus \\
The healthcare information that I receive from the media is helpful \\
Sometimes healthcare information providers (media) make me wonder whether their information is correct \\
I feel confident that I can get all necessary healthcare information from providers (media) \\
I have easy access to health care information that I need from providers (media) \\
I have some doubts about the ability of media to provide correct information \\
I am dissatisfied with healthcare information from providers (media) \\
When I get media information about healthcare, this information is well prepared \\
Healthcare information from providers (media) is presented in a friendly manner \\
\hline
\end{tabular}

Table A5. Health safety during pandemic.

Question
Have you read any health and safety principles against the coronavirus from the media?
Save you carried out simple risk assessments of the coronavirus based on health and safety principles from the media?
Do you know about government health and safety policy programs against the coronavirus from the media?
Has the media made you aware of the hazards of the coronavirus?
Do you believe that you are safe in the pandemic by using safety information from the media?
Do you know where to go at the first sign of the coronavirus using safety information from media?
Has the media provided information on how you can protect yourself against the coronavirus (equipment, actions, etc.)?
Have you heard of anyone from your inner circle who fell ill with the coronavirus despite the provided safety information
from the media?

Table A6. Attentiveness to yourself during pandemic.

Question
So you eat a whole foods-based diet rich in vitamins during the pandemic using reminders from the media?
Do you make time for self-reflection during the pandemic, using reminders from the media?
Do you take time off when sick during the pandemic, using reminders from the media?
Do you get enough sleep during the pandemic, using reminders from the media?
Do you wear clothes you like during the pandemic, using reminders from the media?
Do you take vacations during the pandemic, using reminders from the media?
Do you get medical care when needed during the pandemic, using reminders from the media?
Do you exercise during the pandemic, using reminders from the media?
Do you get regular preventative medical care during the pandemic, using reminders from the media?
Do you engage in fun physical activities during the pandemic, using reminders from the media?

Table A7. Hope during pandemic.

\section{Question}

I can think of many ways to get out of pandemic-based problems based on media information.

Media information encourages me to energetically pursue my goals during the pandemic. I feel tired most of the time because of media news about the pandemic

There are many ways around any pandemic-based problems based on media information.

I can think of many ways to get the things that are important to me during the pandemic based on media information I worry about my health in the pandemic because of media news.

Even when others get discouraged, I know I can find a way to solve pandemic-based problems using media information.

My past experiences in the pandemic have prepared me well for my future, thanks to media information.

I usually find myself worrying during the pandemic because of media information. I meet the goals that I set for myself. 
Table A8. Perceived health risk during pandemic.

Question
How seriously do you think the coronavirus infection is, according to media information?
To what extent can coronavirus infection be prevented according to media information?
To what extent do you believe that you may be infected by the coronavirus in the near future, according to media information?
To what extent are you empowered to take action to ensure your own safety and the safety of your family members according to media
information?
How corned are you about being infected by the coronavirus, according to media information?
information?
Suppose that you have been vaccinated against coronavirus infection. What do you think are your chances of getting the coronavirus
according to media information?
Would you get a vaccine against coronavirus infection if this was advised through social media?
Are the measures taken by the government sufficient to protect your health during the pandemic, according to media information?

Table A9. Perceived irritability during pandemic.

\section{Question}

I consider pandemic alerts/news as annoying

I consider pandemic alerts/news as irritating

I perceive pandemic alerts/news as disturbing

I perceive pandemic alerts/news as intrusive

I feel uncomfortable receiving mobile pandemic alerts in the form of text messages

I believe that the more information I receive (news, alerts), the more I develop a negative feeling toward them

I feel that receiving a larger frequency of alerts and media news negatively influences my attitude

I believe that pandemic alerts/news impair my ability to get along with the people around me

I believe that pandemic alerts/news make me more aggressive than usual

I believe that pandemic alerts/news make me act arrogantly and even rude towards others more than usual

I believe that pandemic alerts/news make me more impatient than usual

I believe that pandemic alerts/news make me likely to get angry about any comment directed at me more than usual

Table A10. Anxiety/depression during pandemic.

Question
I believe that pandemic alerts/news make me feel preoccupied and uneasy more than usual
than usual
In general, I believe that pandemic alerts/news make me feel more worried, likely to anticipate the worst, fearful, and irritable
I believe that pandemic alerts/news make me feel sadder than usual
I believe that pandemic alerts/news make me feel more depressed or "down in the dumps" than usual
I believe that pandemic alerts/news make me feel more ill at ease with myself than usual
I believe that pandemic alerts/news make me feel more stressed and under pressure than usual
I believe that pandemic alerts/news make me feel tired or low-energy more often than usual

Table A11. Mental balance during pandemic.

Question
Score
Despite the constant alerts/news about the pandemic, I live at a normal pace, not doing anything excessively
Despite the constant alerts/news about the pandemic, I am true to myself, acting naturally at all times
during the pandemic
Despite the constant alerts/news about the pandemic, my life is well-balanced between mamily, personal, and professional activities
Despite the constant alerts/news about the pandemic, I feel emotionally balanced
Despite the constant alerts/news about the pandemic, I am optimistic about the future
Despite the constant alerts/news about the pandemic, I am interested in new things
Despite the constant alerts/news about the pandemic, I feel cheerful
Despite the constant alerts/news about the pandemic, I have the energy to spare
Despite the constant alerts/news about the pandemic, I cope with problems well
Despite the constant alerts/news about the pandemic, I feel good about myself


Table A12. Perceived worry during pandemic.

Question

I believe that getting pandemic alerts/news makes me very worried about the coronavirus

I believe that getting pandemic alerts/news makes me very worried that friends or family will be infected I believe that getting pandemic alerts/news makes my worries overwhelm me

I know I should not too much worry about the coronavirus, but after getting pandemic alerts/news, I just cannot help it

Overall, because of pandemic alerts/news, I believe that people that I care about (e.g., grandparents) are at risk of becoming infected I believe that getting pandemic alerts/news makes me spend much of my time worrying about my health

I am taking precautions to prevent infection (e.g., washing hands, avoiding contact with people, avoiding door handles) because of constant reminders from pandemic alerts/news

I believe that getting pandemic alerts/news makes me stock up on supplies to prepare for problems related to the coronavirus

I believe that getting pandemic alerts/news makes me worried that health authorities are not doing enough to deal with the coronavirus

I believe that getting pandemic alerts/news makes me feel worried

\section{Appendix B. Results of Explanatory Factor Analysis (EFA)}

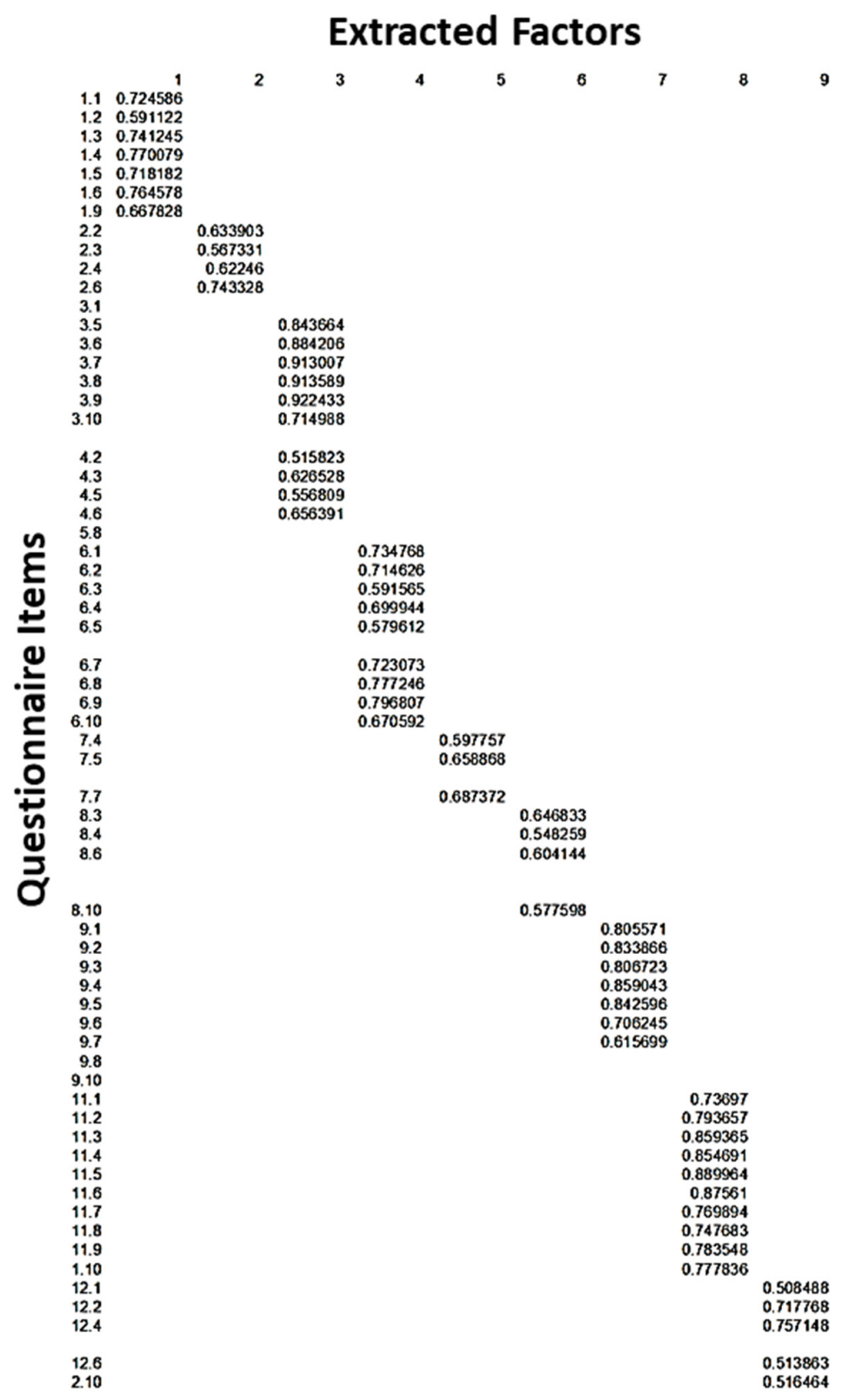

Figure A1. EFA results. 


\section{References}

1. WHO. Novel Coronavirus (2019-nCoV) Situation Report-1, World Health Organization: Coronavirus Disease (COVID-2019) Situation Reports. Available online: https://www.who.int/docs/default-source/coronaviruse/situation-reports/20200121 -sitrep-1-2019-ncov.pdf (accessed on 15 September 2021).

2. Lin, C.Y.; Ding, B.; Xie, Z.; Sun, X.; Li, Z.; Chen, Z.; Niu, M. Asymptomatic novel coronavirus pneumonia patient outside Wuhan: The value of CT images in the course of the disease. Clin. Imaging 2020, 63, 7-9. [CrossRef] [PubMed]

3. Singh, S.; Roy, D.; Sinha, K.; Parveen, S.; Sharma, G.; Joshi, G. Impact of COVID-19 and lockdown on mental health of children and adolescents: A narrative review with recommendations. Psychiatry Res. 2020, 293, 113429. [CrossRef] [PubMed]

4. Luo, T.; Chen, W.; Liao, Y. Social media use in China before and during COVID-19: Preliminary results from an online retrospective survey. J. Psychiatr. Res. 2021, 140, 35-38. [CrossRef] [PubMed]

5. Büssing, A.; Recchia, D.R.; Hein, R.; Deinberg, T. Perceived changes of specific attitudes, perceptions and behaviors during the Corona pandemic and their relation to wellbeing. Health Qual. Life Outcomes 2020, 18, 374. [CrossRef]

6. Steinert, S. Corona and value change. The role of social media and emotional contagion. Eth. Inf. Technol. 2020. [CrossRef]

7. SMHA. COVID-19 and Anxiety. Available online: https://www.heretohelp.bc.ca/infosheet/covid-19-and-anxiety (accessed on 13 August 2021).

8. Al-Dhaheri, A.S.; Bataineh, M.F.; Mohamad, M.N.; Ajab, A.; Marzouqi, A. Impact of COVID-19 on mental health and quality of life: Is there any effect? A cross-sectional study of the MENA region. PLoS ONE 2021, 16, e0249107. [CrossRef] [PubMed]

9. Grossman, E.R.; Benjamin-Neelon, S.E.; Sonnenschein, S. Alcohol Consumption during the COVID-19 Pandemic: A CrossSectional Survey of US Adults. Int. J. Environ. Res. Public Health 2020, 17, 9189. [CrossRef]

10. Winstock, A. GDS COVID-19 Special Edition: Key Findings Report, Global Drug Survey. Available online: https://www. globaldrugsurvey.com/gds-covid-19-special-edition-key-findings-report/ (accessed on 10 November 2020).

11. Brailovskaia, J.; Cosci, F.; Mansueto, G.; Margraf, J. The relationship between social media use, stress symptoms and burden caused by coronavirus (COVID-19) in Germany and Italy: A cross-sectional and longitudinal investigation. J. Affect. Disord. Rep. 2021, 3, 100067. [CrossRef]

12. Susumu, C.; Takashi, I.; Kenji, I.; Asei, I.; Hiroto, K.; Kenneth, M.M.E.; Masahiro, S. The bright and dark sides of social media usage during the COVID-19 pandemic: Survey evidence from Japan. Int. J. Disaster Risk Reduct. 2021, 54, 102034.

13. Ahmad, A.R.; Murad, H.R. The impact of social media on panic during the COVID-19 pandemic in Iraqi Kurdistan: Online questionnaire study. J. Med. Internet Res. 2020, 22, e19556. [CrossRef] [PubMed]

14. Allington, D.; Duffy, B.; Wessely, S.; Dhavan, N.; Rubin, J. Health-protective behaviour, social media usage and conspiracy belief during the COVID-19 public health emergency. Psychol. Med. 2020, 51, 1763-1769. [CrossRef] [PubMed]

15. Aburto, J.M.; Schöley, J.; Kashnitsky, I.; Zhang, L.; Rahal, C.; Missov, T.I.; Mills, M.C.; Dowd, J.B.; Kashyap, R. Quantifying impacts of the COVID-19 pandemic through life-expectancy losses: A population-level study of 29 countries. Int. J. Epidemiol. 2021, dyab207. [CrossRef]

16. Yang, J.; Tian, Y. “Others are more vulnerable to fake news than I Am": Third-person effect of COVID-19 fake news on social media users. Comput. Hum. Behav. 2021, 125, 106950. [CrossRef]

17. Liu, H.; Liu, W.; Yoganathan, V.; Osburg, V.-S. COVID-19 information overload and generation Z's social media discontinuance intention during the pandemic lockdown. Technol. Forecast. Soc. Chang. 2021, 166, 120600. [CrossRef]

18. Ahmad, N.S.; Hussain, Z.; Hamid, H.S.A.; Khairani, A.Z. Roles of social media and counselling support in reducing anxiety among Malaysian during Covid-19 pandemic. Int. J. Disaster Risk Reduct. 2021, 63, 102456. [CrossRef]

19. Pennington, N. Communication outside of the home through social media during COVID-19. Comput. Hum. Behav. 2021, 4 , 100118. [CrossRef] [PubMed]

20. Primack, B.A.; Shensa, A.; Sidani, J.E.; Escobar-Viera, S.G.; Fine, M.J. Temporal Associations between Social Media Use and Depression. Am. J. Prev. Med. 2021, 60, 179-188. [CrossRef] [PubMed]

21. Meshi, D.; Ellithorpe, M.E. Problematic social media use and social support received in real-life versus on social media: Associations with depression, anxiety and social isolation. Addict. Behav. 2021, 119, 106949. [CrossRef] [PubMed]

22. Wang, W.; Wang, M.; Hu, Q.; Wang, P.; Lei, L.; Jiang, S. Upward social comparison on mobile social media and depression: The mediating role of envy and the moderating role of marital quality. J. Affect. Disord. 2020, 270, 143-149. [CrossRef] [PubMed]

23. Nasier, B.; Gibson, K.; Trnka, S. "PM me" or "LOL": Young peoples' observations of supportive and unsympathetic responses to distress on social media. Comput. Hum. Behav. 2021, 124, 106933. [CrossRef]

24. Thorisdottir, I.E.; Sigurvinsdottir, R.; Kristjansson, A.L.; Allegrante, J.P.; Lilly, C.L.; Sigfusdottir, I.D. Longitudinal association 13 a between social media use and psychological distress among adolescents. Prev. Med. 2020, 141, 106270. [CrossRef] [PubMed]

25. Al-Dwaikat, T.N.; Aldalaykeh, M.; Ta'an, W.; Rababa, M. The relationship between social networking sites usage and psychological distress among undergraduate students during COVID-19 lockdown. Heliyon 2020, 6, e05695. [CrossRef] [PubMed]

26. Ho, H.-Y.; Chen, Y.-L.; Yen, C.-F. Different impacts of COVID-19-related information sources on public worry: An online survey through social media. Internet Interv. 2020, 22, 100350. [CrossRef] [PubMed]

27. Su, Y. It doesn't take a village to fall for misinformation: Social media use, discussion heterogeneity preference, worry of the virus, faith in scientists, and COVID-19-related misinformation beliefs. Telemat. Inform. 2021, 58, 101547. [CrossRef]

28. Cincidda, C.; Pizzoli, S.F.M.; Oliveri, S.; Pravettoni, G. Regulation strategies during COVID-19 quarantine: The mediating effect of worry on the links between coping strategies and anxiety. Eur. Rev. Appl. Psychol. 2021, 100671. [CrossRef] 
29. Lodder, G.M.A.; Van Halem, S.; Bülow, A.; van Scheppingen, M.A.; Weller, J.; Reitz, A.K. Daily fluctuations in occupation with and worry about COVID-19. Pers. Individ. Differ. 2021, 182, 111078. [CrossRef]

30. Benesch, C.; Loretz, S.; Stadelmann, D.; Thomas, T. Media coverage and immigration worries: Econometric evidence. J. Econ. Behav. Organ. 2019, 160, 52-67. [CrossRef]

31. Martinez-Garcia, M.; Rabasa, A.; Barber, X. Key factors affecting people's unwillingness to be confined during the COVID-19 pandemic in Spain: A large-scale population study. Sci. Rep. 2021, 11, 18626. [CrossRef] [PubMed]

32. Hu, Y.; Ye, B.; Im, H. Hope and post-stress growth during COVID-19 pandemic: The mediating role of perceived stress and the moderating role of empathy. Pers. Individ. Differ. 2021, 178, 110831. [CrossRef]

33. Mansoor, M. Citizens' trust in government as a function of good governance and government agency's provision of quality information on social media during COVID-19. Gov. Inf. Q. 2021, 38, 101597. [CrossRef]

34. Shareef, M.A.; Kapoor, K.K.; Mukerji, B.; Dwivedi, R.; Dwivedi, Y.K. Group behavior in social media: Antecedents of initial trust formation. Comput. Hum. Behav. 2020, 105, 106225. [CrossRef]

35. Li, S.; Wang, Y.; Xue, J.; Zhao, N.; Zhu, T. The impact of COVID-19 epidemic declaration on psychological consequences: A study on active Weibo users. Int. J. Environ. Res. Public Health 2020, 17, 2032. [CrossRef] [PubMed]

36. Mechanic, D. Effects of psychological distress on perceptions of physical health and use of medical and psychiatric facilities. J. Hum. Stress 1978, 4, 26-32. [CrossRef] [PubMed]

37. Sänger, J.; Bechtold, L.; Schoofs, D.; Blaszkewicz, M.; Wascher, E. The influence of acute stress on attention mechanisms and its electrophysiological correlates. Front. Behav. Neurosci. 2014, 8, 353. [CrossRef] [PubMed]

38. Zavlis, O.; Butter, S.; Bennett, K.; Hartman, T.; Hyland, P.; Mason, L.; McBride, O.; Murphy, J.; Gibson-Miller, J.; Levita, L.; et al. How Does the COVID-19 Pandemic Impact on Population Mental Health? A Network Analysis of COVID Influences on Depression, Anxiety and Traumatic Stress in the UK Population. Psychol. Med. 2021, 1-9. Available online: https:/ / www.cambridge.org/core/journals/psychological-medicine/article/how-does-the-covid19-pandemic-impact-onpopulation-mental-health-a-network-analysis-of-covid-influences-on-depression-anxiety-and-traumatic-stress-in-the-ukpopulation/30A589E271420FB6D88A4CCF3B14FAD1 (accessed on 29 November 2021). [CrossRef]

39. Chung, N.; Kwon, S.J. Effect of trust level on mobile banking satisfaction: A multi-group analysis of information system success instruments. Behav. Inf. Technol. 2009, 28, 549-562. [CrossRef]

40. WHO. 2019. Available online: https://www.who.int/en/ (accessed on 11 August 2021).

41. Uittenbogaard, C.; Ahlskog, T.; Grönlund, B. Trygghet i Samhället; Jure Förlag AB: Stockholm, Sweden, 2018.

42. Merriam-Webster. Attentiveness. Available online: https://www.merriam-webster.com/thesaurus/attentiveness (accessed on 13 August 2021).

43. Snyder, C. Hope Theory: Rainbows in the Mind. Psychol. Inq. 2002, 13, 249-275. [CrossRef]

44. Li, Z.; Hu, B. Perceived health risk, environmental knowledge, and contingent valuation for improving air quality: New evidence from the Jinchuan mining area in China. Econ. Hum. Biol. 2018, 31, 54-68. [CrossRef] [PubMed]

45. Cherry, K. What Is Irritability? Available online: https://www.verywellmind.com/irritability-definition-symptoms-traits-causestreatment-5088062 (accessed on 13 August 2021).

46. ADAA. Depression. Available online: https://adaa.org/understanding-anxiety/depression (accessed on 13 August 2021).

47. Vocabulary. Mental Balance. Available online: https://www.vocabulary.com/dictionary/mental\%20balance\#: :text= Definitions\%20of\%20mental\%20balance, of\%20emotional\%20and\%20behavioral\%20adjustment (accessed on 13 August 2021).

48. Hirsch, C.R.; Perman, G.; Hayes, S.; Eagleson, C.; Mathews, A. Delineating the Role of Negative Verbal Thinking in Promoting Worry, Perceived Threat, and Anxiety. Clin. Psychol. Sci. 2015, 3, 637-647. [CrossRef]

49. Meyer, T.J.; Miller, M.L.; Metzger, R.L.; Borkovec, T.D. Development and validation of the Penn State Worry Questionnaire. Behav. Res. Ther. 1990, 28, 487-495. [CrossRef]

50. Sexton, J.B.; Helmreich, R.L.; Neilands, T.B.; Rowan, K.; Vella, K.; Boyden, J.; Roberts, P.R.; Thomas, E.J. The Safety Attitudes Questionnaire: Psychometric properties, benchmarking data, and emerging research. BMC Health Serv. Res. 2006, 6, 44. [CrossRef] [PubMed]

51. Haghirian, P.; Madlberger, M. Consumer Attitude toward Advertising via Mobile Devices—An Empirical Investigation Among Austrian Users. In Proceedings of the 13th European Conference on Information Systems, Regensburg, Germany, 26-28 May 2005.

52. Ünal, S.; Erciş, A.; Keser, E. Attitudes towards Mobile Advertising-A Research to Determine the Differences between the Attitudes of Youth and Adults. Procedia Soc. Behav. Sci. 2011, 24, 361-377. [CrossRef]

53. Gerbaudo, P. Social media and populism: An elective affinity? Media Cult. Soc. 2018, 40, 745-753. [CrossRef]

54. Liu, Q.; Wang, Z. Perceived stress of the COVID-19 pandemic and adolescents' depression symptoms: The moderating role of character strengths. Pers. Individ. Differ. 2021, 182, 111062. [CrossRef] [PubMed]

55. Oh, H.; Marinovich, C.; Rajkumar, R.; Besecker, M.; Zhou, S.; Jacob, L.; Koyanagi, A.; Smith, L. COVID-19 dimensions are related to depression and anxiety among US college students: Findings from the Healthy Minds Survey 2020. J. Affect. Disord. 2021, 292, 270-275. [CrossRef] [PubMed]

56. Zhang, N.; Shi, W.; Feng, D.; Fang, W.; Zeng, Q.; Qu, Y. A preliminary study on the anxiety and depression situation and psychological intervention of the first-line medical staff in our hospital during the COVID-19 epidemic. J. Clin. Neurosci. 2021, 91, 9-12. [CrossRef] 
57. Sasaki, N.; Kuroda, R.; Tsuno, K.; Kawakami, N. Exposure to media and fear and worry about COVID-19. Psychiatry Clin. Neurosci. 2020, 74, 501-502. [CrossRef]

58. Liu, M.; Zhang, H.; Huang, H. Media exposure to COVID-19 information, risk perception, social and geographical proximity, and self-rated anxiety in China. BMC Public Health 2020, 20, 1649. [CrossRef] [PubMed]

59. Vacondio, M.; Priolo, G.; Dickert, S.; Bonini, N. Worry, Perceived Threat and Media Communication as Predictors of Self-Protective Behaviors During the COVID-19 Outbreak in Europe. Front. Psychol. 2021, 12, 231. [CrossRef]

60. Bendau, A.; Petzold, M.B.; Pyrkosch, L. Associations between COVID-19 related media consumption and symptoms of anxiety, depression and COVID-19 related fear in the general population in Germany. Eur. Arch. Psychiatry Clin. Neurosci. 2021, 271, 283-291. [CrossRef] [PubMed]

61. Abramson, L.Y.; Alloy, L.B.; Metalsky, G.I. Hopelessness depression, a theory-based subtype of depression. Psychol. Rev. 1989, 96, 358-372. [CrossRef]

62. Zhang, X.; Zou, R.; Liao, X.; Bernardo, A.; Du, H.; Wang, Z.; Cheng, Y.; He, Y. Perceived Stress, Hope, and Health Outcomes among Medical Staff in China during the COVID-19 Pandemic. Front. Psychiatry 2021, 11, 588008. [CrossRef] [PubMed]

63. Larsen, D.J.; Stege, R. Hope-focused practices during early psychotherapy sessions: Part I: Implicit approaches. J. Psychother. Integr. 2010, 20, 271-292. [CrossRef]

64. Eliott, J.A.; Olver, I.N. Hope, life, and death: A qualitative analysis of dying cancer patients' talk about hope. Death Stud. 2009, 33, 609-638. [CrossRef] [PubMed]

65. Nicomedes, C.; Avila, R. An analysis on the panic during COVID-19 pandemic through an online form. J. Affect. Disord. 2020, 276, 14-22. [CrossRef]

66. Wikipedia. Moral Panic. Available online: https://en.wikipedia.org/wiki/Moral_panic\#: :text=A\%20moral\%20panic\%20is\% $20 \mathrm{a}$, of $\% 20 \mathrm{a} \% 20$ community $\% 20$ or $\% 20$ society.\&text=Some $\% 20$ moral $\% 20$ panics $\% 20$ can $\% 20$ become, $\% 22$ Red $\% 20$ Scare $\% 22 \% 2$ 0and\%20terrorism (accessed on 11 August 2021).

67. Coleman, S.; Ross, K. The Media and the Public; John Wiley \& Sons: Hoboken, NJ, USA, 2010.

68. Powell, A.; Stratton, G.; Cameron, R. Digital Criminology: Crime and Justice in Digital Society; Routledge: London, UK, 2018.

69. Trottier, D. Coming to terms with shame: Exploring mediated visibility against transgressions. Surveill. Soc. 2018, 16, 170-182. [CrossRef] 